\title{
MACHINING OF RESILIENT WHEELSETS ON WHEEL-TURNING LATHES
}

\author{
FILIPOWICZ, K.; BIEDUNKIEWICZ, W.; \\ KROLIKOWSKI, M. \& GRZESIAK, D.
}

Abstract: Manuscript presents modelling and computations of machining process of turning resilient wheel on wheel-turning lathe with friction drive using FEM method. Presented research is a part of research performed in Institute of Mechanical Technology in West Pomeranian University of Technology in order to enable regeneration of resilient wheelsets using wheel-turning lathes with friction drive, commonly used for regeneration of heavy railway wheelsets.

Key words: resilient wheels, FEM, turning, technology
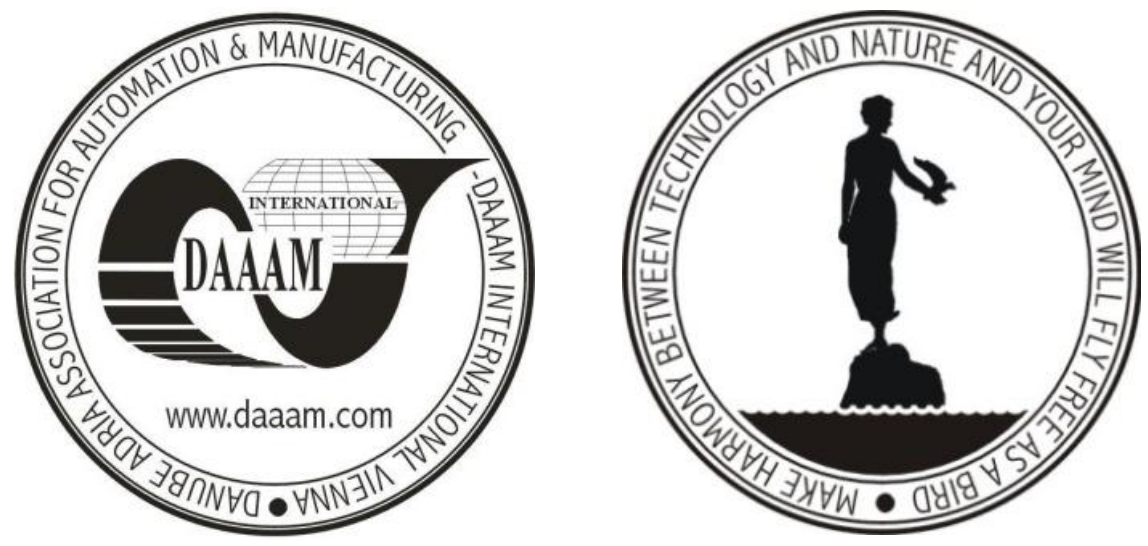

Authors' data: Msc. Eng. Filipowicz, K[rzysztof]; Univ. Prof. Phd. Eng. Biedunkiewicz, W[itold]; Phd. Eng. Krolikowski, M[arcin]; Msc. Eng. Grzesiak, D[ariusz], West Pomeranian University of Technology, ul. Piastów 17, 70- 310 Szczecin,Poland,Krzysztof.Filipowicz@zut.edu.pl,Witold.Biedunkiewicz@ zut.edu.p 1, Dariusz.Grzesiak@zut.edu.pl, Marcin.Krolikowski@zut.edu.pl

This Publication has to be referred as: Filipowicz, K[rzysztof]; Biedunkiewicz, W[itold]; Krolikowski M[arcin] \& Grzesiak, D[ariusz] (2010). Machining of Resilient Wheelsets on Wheel-Turning Lathes, Chapter 05 in DAAAM International Scientific Book 2010, pp. 041-048, B. Katalinic (Ed.), Published by DAAAM International, ISBN 978-3-901509-74-2, ISSN 1726-9687, Vienna, Austria

DOI: $10.2507 /$ daaam.scibook.2010.05 


\section{Introduction}

Resilient wheels are made to reduce noise, and improve comfort of travelling with lightweight railways. That is why they are commonly used in city rail wagons. Reduction of vibrations is achieved by inserting elastic layer between hard steel wheel tyre, and wheel centre. This solution is very efficient for vibrations damping while wagon runs, but may be a problem during turning of such wheelset on axleturning lathes. Especially that shape of wheel is complicated and it has to be done very accurately. The problem is negligible while turning wheels without removing them from the car with undertruck wheel-turning lathes. Construction of this lathes simulates conditions of normal work of wheel, what helps to obtain required shape. Problem in this case is that to renovate wheels all wagon must be delivered to machine tool working space and the same it is out of order for all the renovation cycle of every wheelset.

Friction drive axle-turning lathes are working with single unmounted wheelset. They were made for turning of heavy railway wheels to avoid a risk of destruction of wheels that were turned with classical lathes with self-locking dog. Using a selflocking dogs while machining is a cause of formation of notches on wheel tyres, what was direct cause of few major accidents of high speed trains in Europe. Friction drive lathes use for making machined wheels rotate three rollers pressed with high force to the wheel instead of dogs that sharp edges are pressed to a wheel surface. As Friction drive axial lathes started to be efficiently used for regeneration of warn railway tyres, there came the idea of using it also for regeneration of resilient wheelsets. So there was a need of performing research if such turning is possible.

One of polish companies that builds friction drive wheel-turning lathes asked West Pomeranian University of Technology to perform research to check what problems occur during the machining of wheelsets on axial lathes with friction drive and to work out a technology suitable to use this kind of machines for regeneration of resilient wheelsets without disassembling wheels. In order to achieve some preliminary results it was decided to use FEM model to check if turning of resilient wheelsets on friction drive lathe is possible.

\section{Research preparation}

First problem was to find out the details of construction of resilient wheels. There are few kinds of construction, but we decided to create model of most flexible wheels in purpose to get the most adverse conditions for machining. Chosen wheels has dumping inserts made as small pieces of elastomer arranged between hub and tyre of wheel with empty spaces between them (as shown on Fig. 1.) what can cause appearing of vibrations during machining. This construction is also disadvantageous because of large distance between hub and tyre which must be filled with elastic inserts and therefore such wheel is not very rigid . 


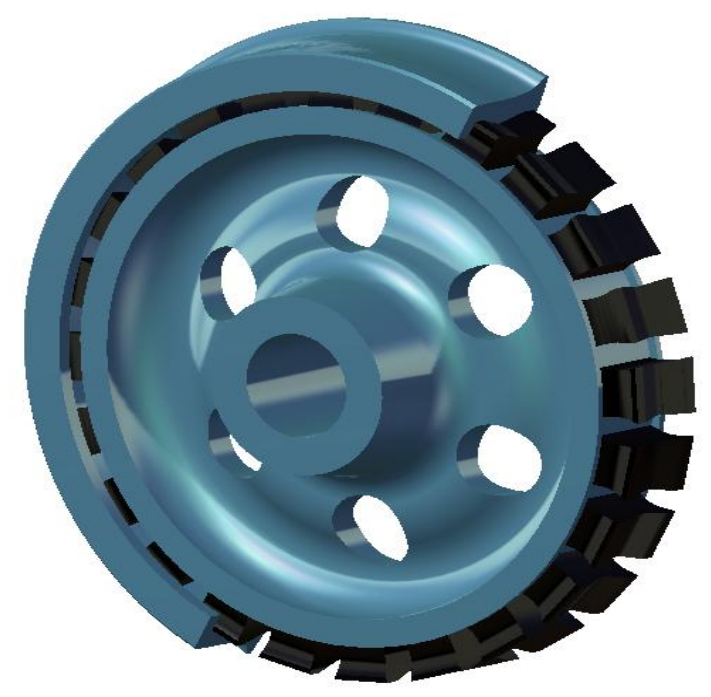

Fig. 1. Pictorial drawing of chosen resilient wheel construction

Material properties of steel used for wheel tyres and hubs was taken from European Standards, but material used for elastic inserts is not normalized, and it was difficult to find any information about its mechanical and physical properties needed for modeling. Therefore it was necessary to perform tests of material properties of elastic inserts used for resilient wheels to use them for FEM model. This tests was performed in material strength laboratory possessed by West Pomeranian University of Technology. New and used inserts was examined for check if the properties of elastomer changed during the usage of resilient wheel.

Independently there were performed tests of machining of steel used for wheel tyres. This test was necessary to determine cutting forces appearing during turning of wheelset. Normally machining of wheels is performed with extremely high cutting parameters what requires high power of lathe, and using special tools (fig. 2.). West Pomeranian Technical University does not have enough powerful and big lathes to perform cutting forces tests on actual wheelset.

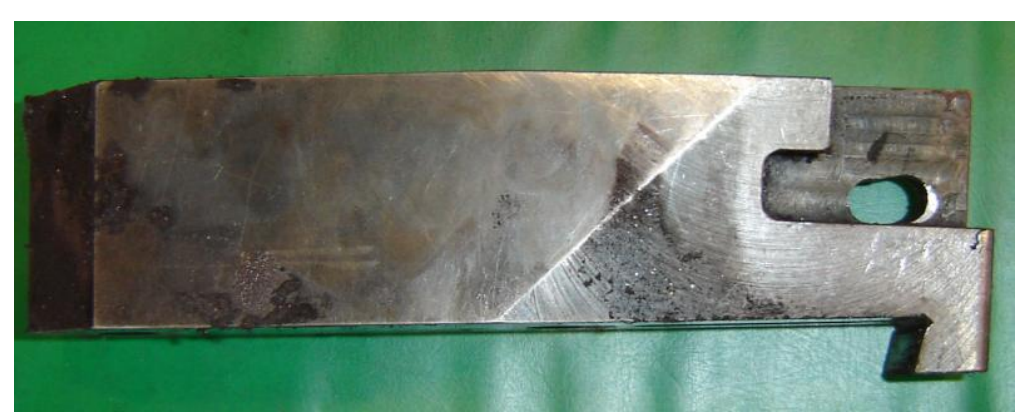

Fig. 2. Standard tool used on wheel-turning lathe

Another problem is that tools used on wheel-turning lathes are specially designed for this machines to be very stiff and durable and it is impossible to use this tools with standard lathes.

Therefore it was necessary to build special tool with inserted force meter, and perform measurements on a working wheel-turning lathe (Fig. 3.). 


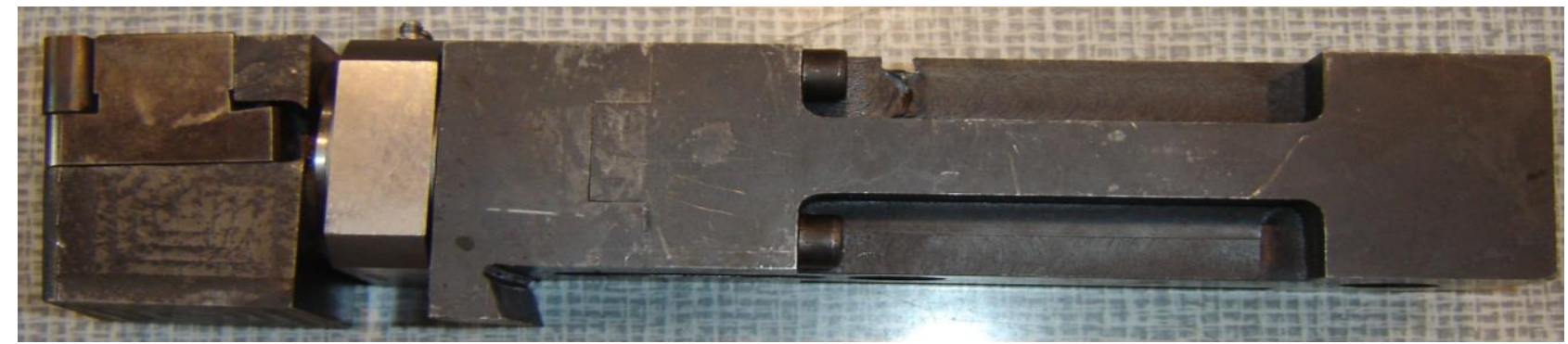

Fig. 3. Special tool with inserted force meter

Results of those tests was used to create FEM model of wheel, and check the deformation of resilient wheel in conditions similar with machining process. Sample of measured values of cutting force $\left(F_{c}\right)$ is shown on fig. 4 .

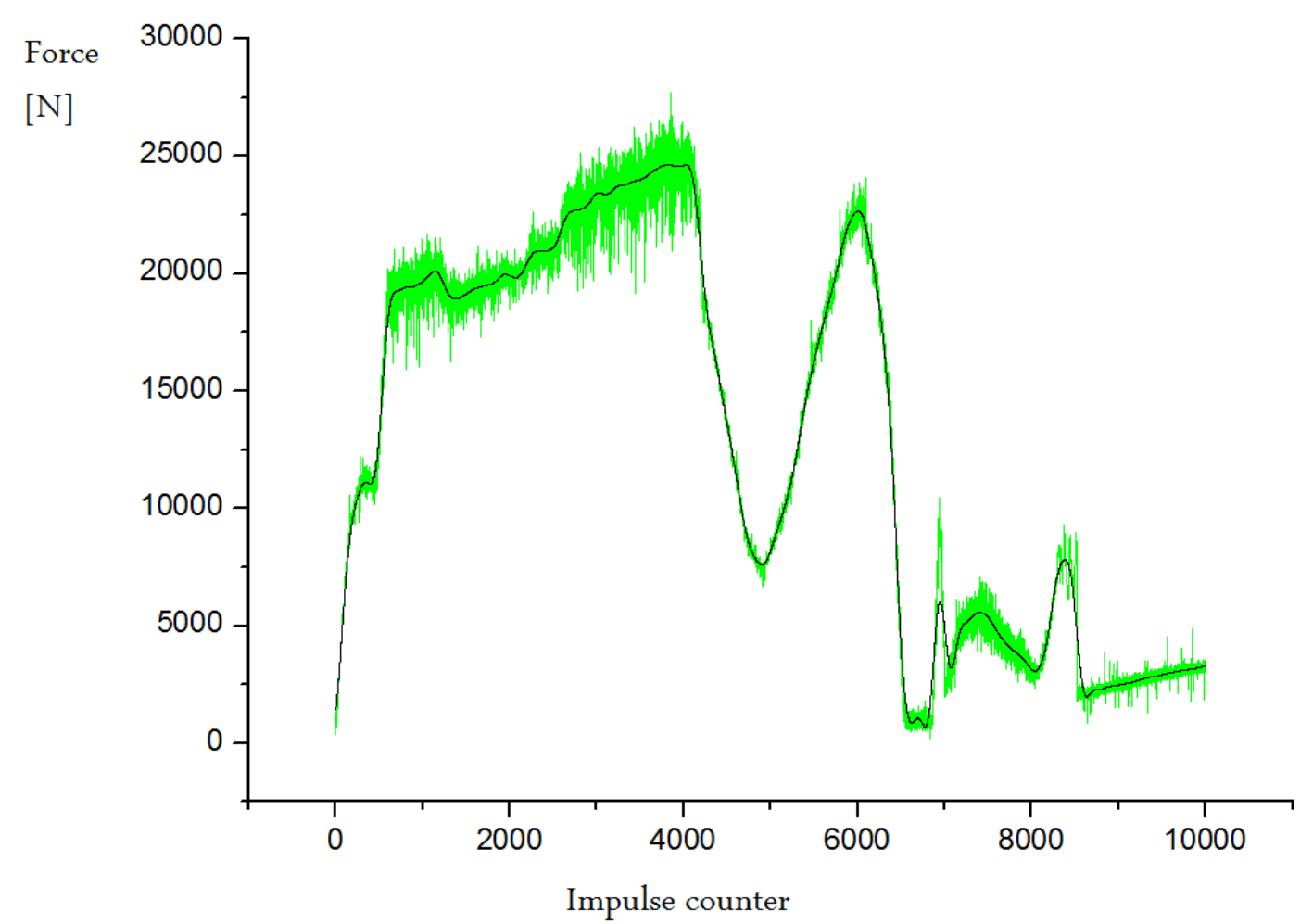

Fig. 4. Sample results of measurment of cutting force $\left(F_{c}\right)$

\section{Modeling and computations}

Computations was performed using computer FEM program COSMOSM 2.95. To obtain possibly accurate results applied model was made of small solid elements that enabled to input forces in distances made by cutting blade during rotation of wheel by angle of 1 degree. This enabled application of load similar to real load during machining process. Model concern machining of one wheel fastened with revolving centre and driven by 3 rollers pressed to wheel with high forces and machined with blade sloped with angle 30 degrees from vertical direction what is feature of particular lathe what facilitates removing chips from working space of the machine. 
Force of rollers pressing and their geometrical localisation was taken from technical information of wheel-turning lathe TUU-1250 which will be used to performing a verification of achieved results.

Preliminary computation was performed to confirm suspicions that deformation of wheel hub is low and can be omitted in further considerations, what allowed to reduce model to elements of tyre and elastic inserts only. Removed hub was replaced by displacements simulating influence of hub on inserts.

First computations was made in coplanar force system perpendicular to wheel axis. Driving rollers, and cutting tool was simulated by forces and fastening was simulated by displacement in the inner side of elastic inserts (as shown on Fig. 5.).
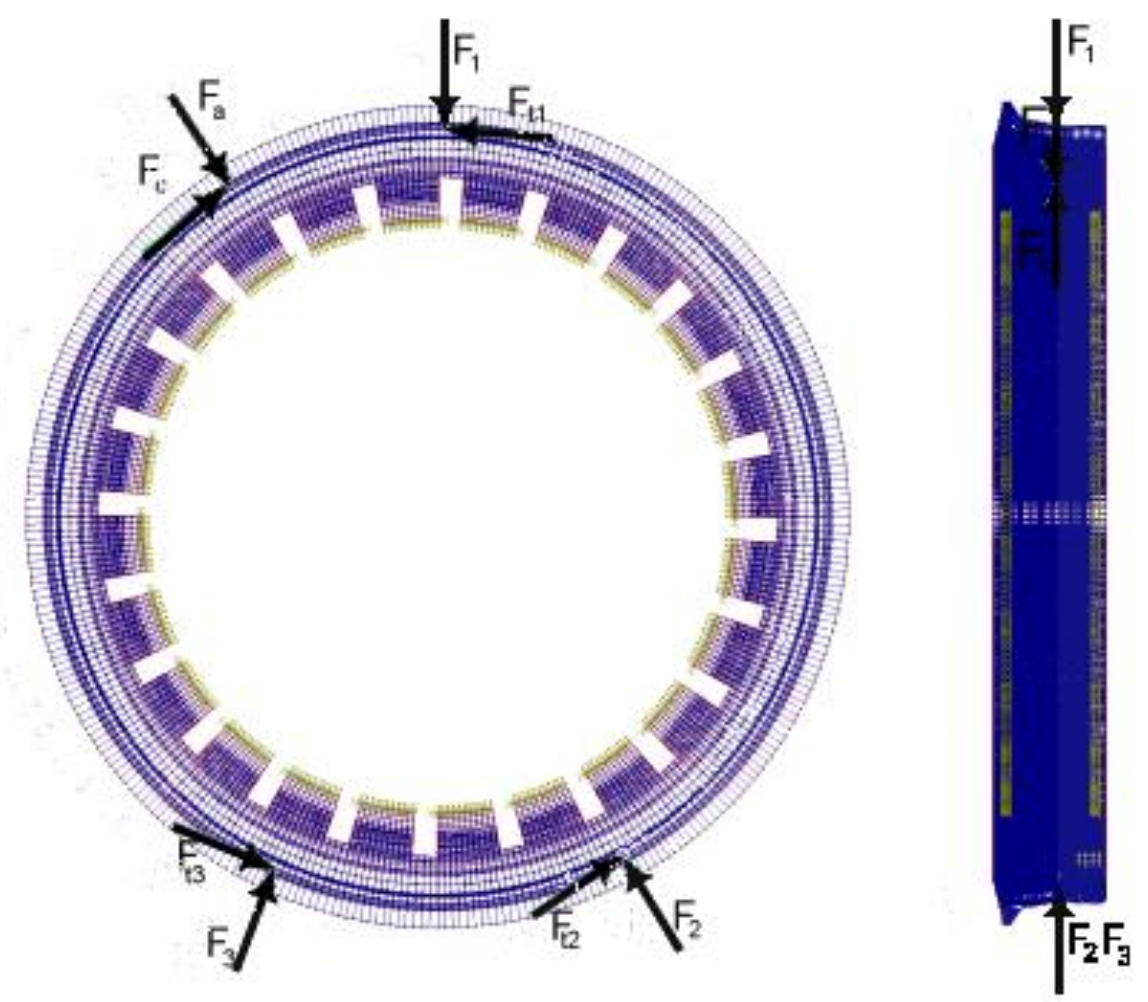

Fig. 5. Placement of forces on first FEM wheel model

Forces $F_{1}, F_{2}$ and $F_{3}$ are forces of rollers pressing and their values are:

$$
\begin{aligned}
& \mathrm{F}_{1}=60000 \mathrm{~N} \\
& \mathrm{~F}_{2}=\mathrm{F}_{3}=25000 \mathrm{~N}
\end{aligned}
$$

Forces $F_{a}$ and $F_{c}$ are measured cutting forces and their values are:

$$
\mathrm{F}_{\mathrm{a}}=\mathrm{F}_{\mathrm{c}}=20000 \mathrm{~N}
$$

Forces $F_{t 1}, F_{t 2}$ and $F_{t 3}$ are applied to counterbalance cutting force $F_{c}$

Presented forces was moved along the circumference of wheel to check the influence of empty spaces between elastic inserts to the radial deformation of tyre measured in point of cutting force load. Every time position of each force against other forces was the same. To check one empty space, and one insert there was needed fifteen different analyses every with forces rotated by 1 degree more then previous. Achieved deformations are shown on Fig. 6. 
Filipowicz, K.; Biedunkiewicz, W.; Krolikowski, M. \& Grzesiak, D.: Machining ...

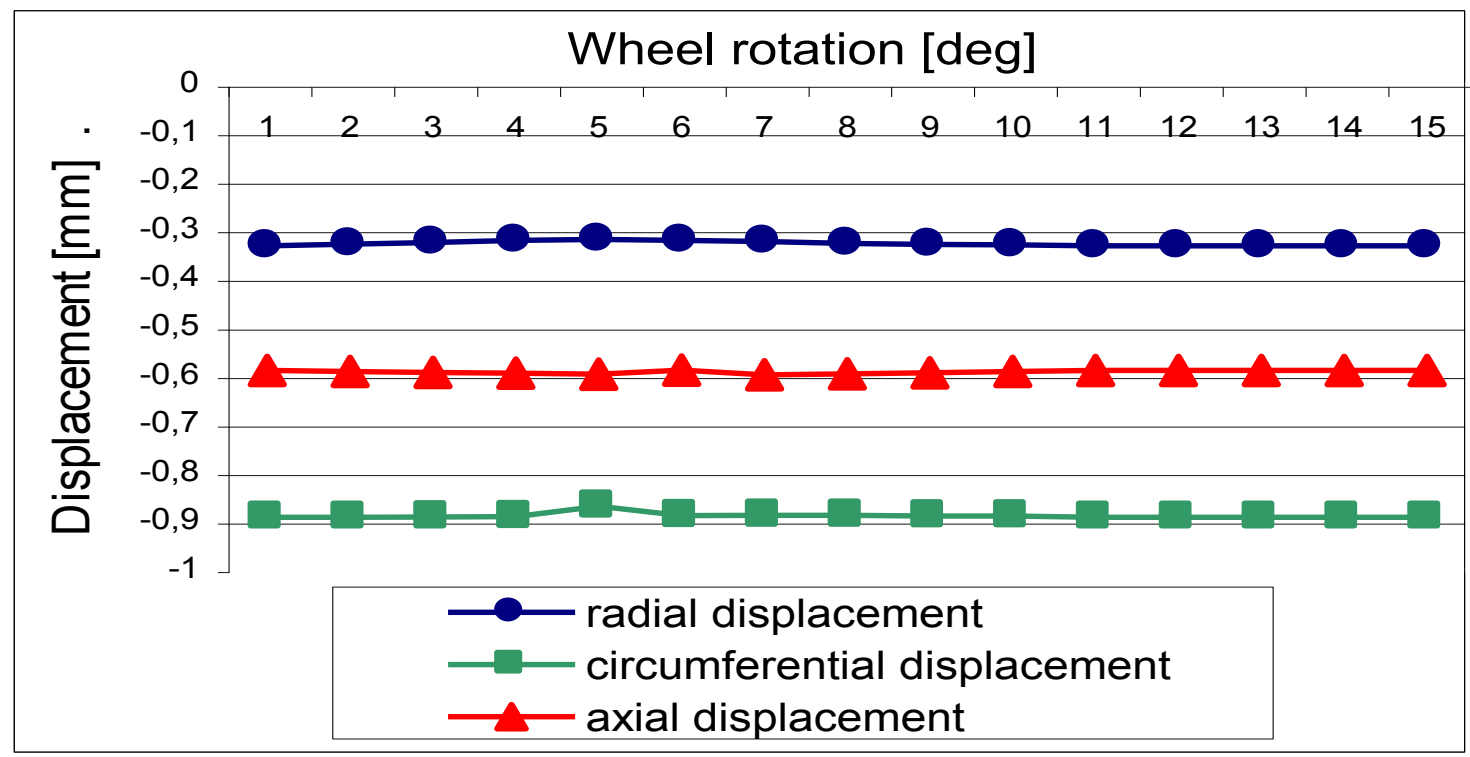

Fig. 6. Displacement of node with applied cutting forces in dependence on angular position of machined wheel

As one can see influence of empty spaces between inserts on deformation is very small. What is significant on the diagram is that there is a large displacement in axial direction (marked with triangles) although there is no force acting in that direction. Circumferential displacement appeared because main cutting force $\left(\mathrm{F}_{\mathrm{c}}\right)$ was not fully counterbalanced by rest of the forces, but it has no influence on results of research.

Next step is model with applied axial forces (Fig. 7.).
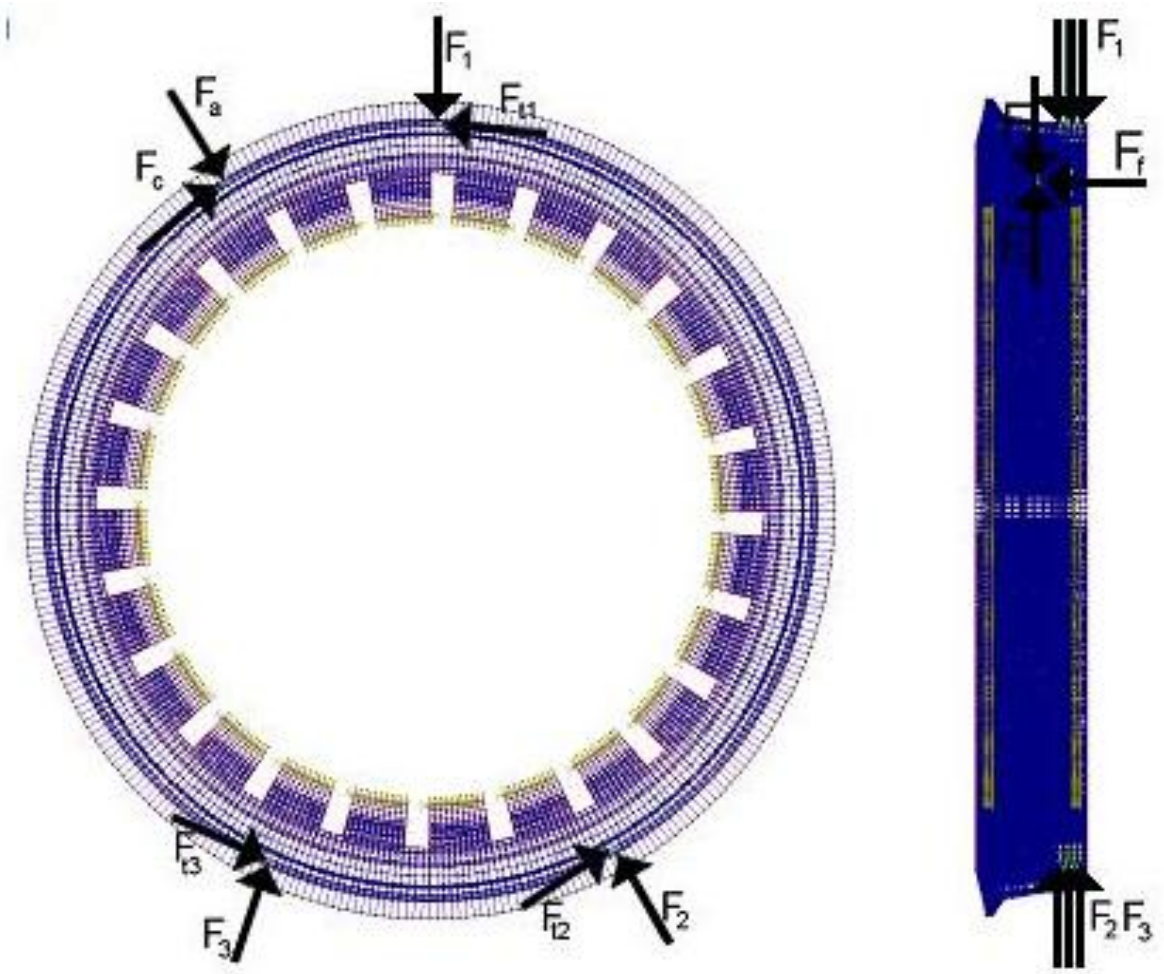

Fig. 7. Placement of forces on second FEM wheel model 
Values of forces has not been changed only one force has been added, it is axial (feed) component of cutting force -

$$
\mathrm{F}_{\mathrm{f}}=10000 \mathrm{~N}
$$

This model includes also removing of allowance from machined surface. This simulation also was made in purpose to enable to check how wheel tyre would react while material is removed from beneath the rollers. On the diagram of axial displacement (on fig. 8 marked with triangles) it is seen as small refractions in positions 7 and 9. That is why forces of rollers pressing has been divided into three smaller forces in a row and changed while removing elements from places where those forces was applied. Simulation of allowance removing has been realized by removing rows of elements along feed of tool machining contour of wheel tyre. This case needed 21 consecutive computations, every one for every removed row of material (elements). Also cutting forces was applied in different position in each case to simulate movement of cutting blade.

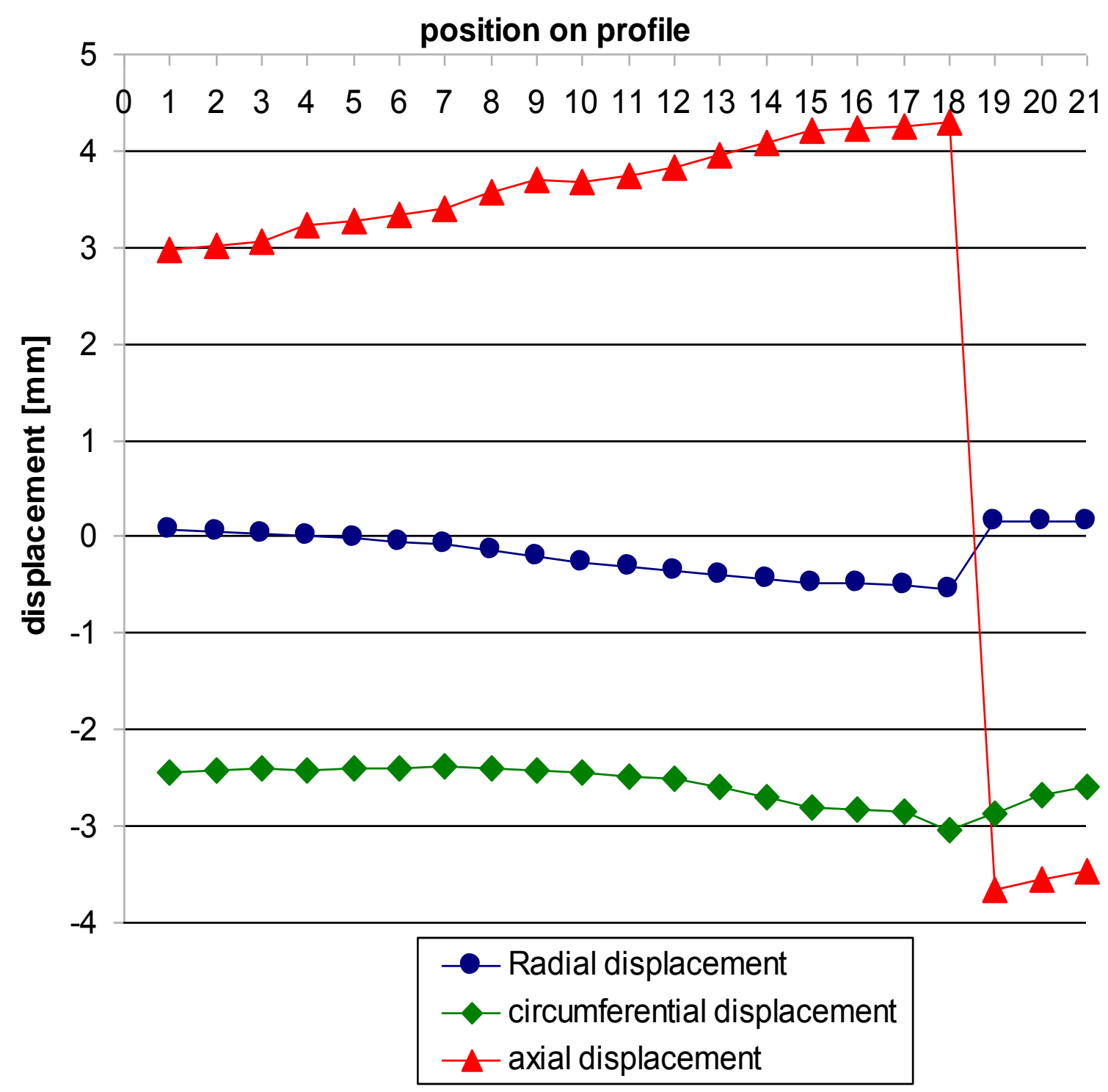

Fig. 8. Displacements of nodes with applied cutting forces in dependence on allowance removing 
Results show dependence of displacements in point of machining on different position of cutting blade on tyre profile.

Sudden change of displacement values between position 18 and 19 on diagram is caused by machining part of profile with opposite feed direction what was modelled according to real conditions.

As it has been expected adding axial (feed) component to model caused high increase of values of axial displacement .

Values of radial displacement did not made any significant change and still are negligibly small.

\section{Conclusions}

Although cutting forces are very high, values of radial displacement are not big, and they don't have influence on geometry of machined tyre, especially while turning.

Discontinuity of elastic insert also has small, negligible influence on deformations of machined wheel

The biggest problem in turning resilient wheelsets on wheel-turning lathes with friction drive appears to be axial deformation of wheel during the machining process. As machining is performed partly in two opposite directions this deformation has direct influence on geometry of machined profile. Also such big displacement can be dangerous for elastic inserts and may cause damage of wheelset.

Obtained results must be verified in real machining in the following part of research. Verification will show if used simple model of machined wheel gives appropriate results of values and shape of displacement of wheel caused by cutting forces.

\section{References}

Górski, E. (1999) Poradnik frezera (Milling handbook). WNT, Warszawa.

Grzesik, W. (1998) Podstawy skrawania materiatów metalowych (Basics of machining of metalic materials). WNT, Warszawa.

Olszak, W. (2001) Obróbka skrawaniem i narzędzia, Rozdziat 5 - Proces skrawania (Machining and tools. Part 5-machining process). Wydawnictwo Politechniki Szczecińskiej, Szczecin.

Zienkiewicz, O.C.; Taylor, R.L \& ZHU. J.Z. (2005) The Finite Element Method: its Basis and Fundamentals. Elsevier Buterrworth-Heinemann, ISBN 0-75066320-0 ,Oxford

***Collective work(1990) Poradnik inżyniera - Obróbka skrawaniem, (Engineer's handbook-Machining),vol. II. WNT, Warszawa 